\title{
Enhanced Photocatalytic Hydrogen Generation by Optimized Plasmonic Hot Electron Injection in Structure-Adjustable Au-ZnO Hybrids
}

\author{
Youlong Chen ${ }^{1}$, Liang Ma ${ }^{1, *} \mathbb{D}$ and Sijing Ding ${ }^{2, *}$ \\ 1 Hubei Key Laboratory of Optical Information and Pattern Recognition, Wuhan Institute of Technology, \\ Wuhan 430205, China; chenyoulong2@126.com \\ 2 School of Mathematics and Physics, China University of Geosciences (Wuhan), Wuhan 430074, China \\ * Correspondence: maliang@wit.edu.cn (L.M.); dingsijing@cug.edu.cn (S.D.); Tel.: +86-027-8799-2089 (L.M.); \\ +86-027-6788-3091(S.D.)
}

Received: 8 March 2020; Accepted: 22 March 2020; Published: 1 April 2020

\begin{abstract}
Plasmonic Au-ZnO hybrids with adjustable structures (including Au-decorated $\mathrm{ZnO}$ and core-shell Au@ZnO with dense and porous $\mathrm{ZnO}$ shells) and the optimized hot electron-driven photocatalytic activity were successfully prepared. It was found that the Au@ZnO core-shell hybrids with porous morphology had the highest plasmon-enhanced photocatalytic hydrogen generation activity under visible light irradiation. The wavelength-dependent photocatalytic tests verified that $\mathrm{Au} @ \mathrm{ZnO}$ with porous $\mathrm{ZnO}$ shells had the highest apparent quantum efficiency upon resonance excitation. The ultrafast transient absorption measurements revealed that $\mathrm{Au} @ \mathrm{ZnO}$ with porous $\mathrm{ZnO}$ shells had the fastest plasmon-induced hot electron injection, which was thought to be the reason for the improved photocatalytic activity. This work might provide a promising route to designing photocatalytic and photoelectric materials.
\end{abstract}

Keywords: nanoparticles; plasmon; photocatalysis; hot electron injection; metallic composites

\section{Introduction}

Hot electron-driven photocatalysis by plasmonic metal-semiconductor hybrids shows great potential in the field of solar energy conversion [1-10]. Hot electrons, which are generated from the nonradiative relaxation of localized surface plasmons, are more energetic than those generated by direct photoexcitation [11-15]. The maximum utilization of hot electrons is significantly important to improve the photocatalytic performance of metal-semiconductor hybrids [16-22]. Several strategies have been proposed to optimize the hot electron injection in plasmonic composites, such as enhancing the near field of plasmonic metal nanocrystals [23-25], selectively placing a semiconductor on the position, where a strong near field is located [26,27]. However, the current strategies mainly focus on adjusting the plasmonic properties of metal nanocrystals and the positions of semiconductors, and few reports concentrate on manipulating the morphology of semiconductors for better reception of hot electrons.

In this work, structure-adjustable $\mathrm{Au}-\mathrm{ZnO}$ hybrids were used for optimizing hot electron-driven photocatalysis. Three types of $\mathrm{Au}-\mathrm{ZnO}$ hybrids, including Au-decorated $\mathrm{ZnO}(\mathrm{Au} / \mathrm{ZnO})$ and core-shell $\mathrm{Au} @ \mathrm{ZnO}$ with dense (Au@dense $\mathrm{ZnO}$ ) and porous shells (Au@porous $\mathrm{ZnO}$ ), were prepared for photocatalytic hydrogen generation from water splitting. It was found that core-shell Au@porous $\mathrm{ZnO}$ hybrids possessed the highest photocatalytic hydrogen generation under light irradiation $(\lambda>420 \mathrm{~nm})$, which were 2.75, 1.34, and 1.14 times those of the pure $\mathrm{ZnO}, \mathrm{Au} / \mathrm{ZnO}$, and $\mathrm{Au} @$ dense $\mathrm{ZnO}$, respectively. The enhanced mechanism can be ascribed to the enhanced utilization efficiency of hot electrons caused by the porous $\mathrm{ZnO}$ shells. 


\section{Results and Discussion}

The detailed morphologies of the structure-adjustable Au-ZnO hybrids are presented in Figure 1. The initial Au nanospheres had an average diameter of $18 \pm 2 \mathrm{~nm}$ (see Figure 1a). Figure $1 \mathrm{~b}$ displays the TEM image of the Au-decorated $\mathrm{ZnO}$ hybrids, demonstrating that the Au nanospheres were randomly attached on $\mathrm{ZnO}$. The TEM image of the core-shell Au@porous ZnO is shown in Figure 1c. The $\mathrm{ZnO}$ nanoshells showed a well-defined porous structure and had an average thickness of $45 \pm 3 \mathrm{~nm}$. Figure 1d exhibits the TEM image of Au@dense ZnO. The ZnO nanoshells displayed a dense structure and had an average thickness of $44 \pm 3 \mathrm{~nm}$.

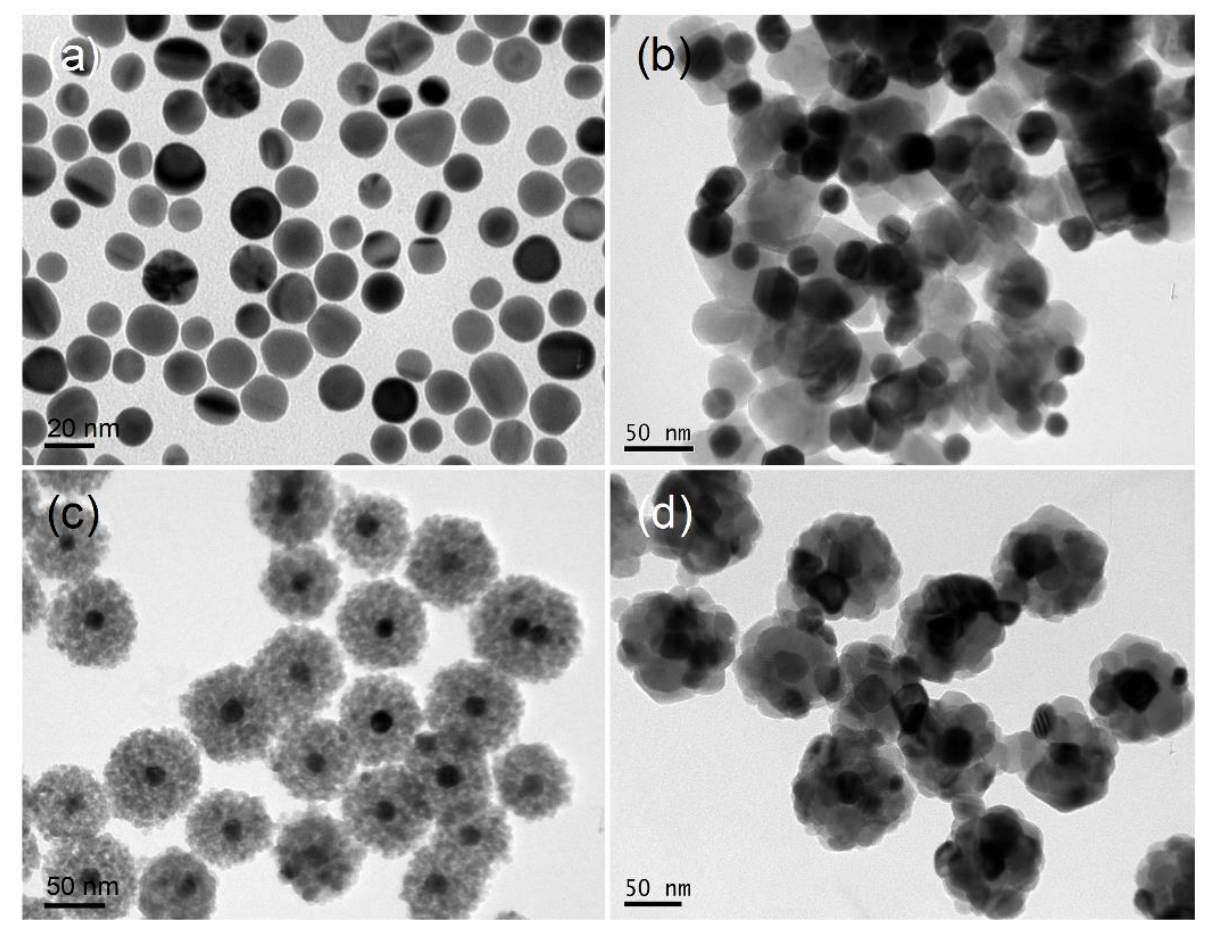

Figure 1. TEM images of $\mathrm{Au}(\mathbf{a}), \mathrm{Au} / \mathrm{ZnO}(\mathbf{b})$, and $\mathrm{Au} @ \mathrm{ZnO}$ with porous (c) and dense (d) shells.

The high-resolution TEM (HRTEM) images and the XRD patterns were obtained to elucidate the detailed morphologies and crystalline structures of the Au-ZnO hybrids. Figure 2a,b displays the XRD patterns and EDS spectra of the structure-adjustable Au-ZnO hybrids. The phase of Au and $\mathrm{ZnO}$ can be observed in the three types of $\mathrm{Au}-\mathrm{ZnO}$ hybrids. From the EDS results, the presences of $\mathrm{Au}$, $\mathrm{Zn}$, and $\mathrm{O}$ elements can be confirmed. Figure 2c exhibits the HRTEM image of single Au@porous $\mathrm{ZnO}$ nanoparticles and demonstrates that the holes (circled by a white dashed line) were randomly distributed in the whole shell region. The average diameter of the holes was approximately $4 \mathrm{~nm}$. Figure $2 \mathrm{~d}$ displays the lattice of the region labelled in Figure 2c. The well-resolved lattice plane distance of $0.261 \mathrm{~nm}$ can be ascribed to the (002) plane of $\mathrm{ZnO}$. The corresponding fast Fourier transform (FFT) analyses of the red labelled region are shown in Figure 2e, which also indicated the existence of the $\mathrm{ZnO}$ lattice plane. 

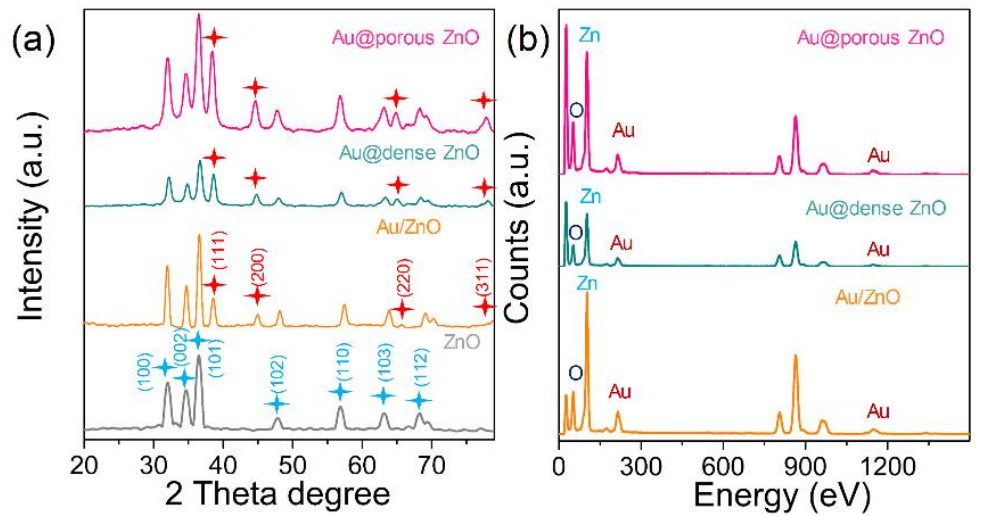

(c)
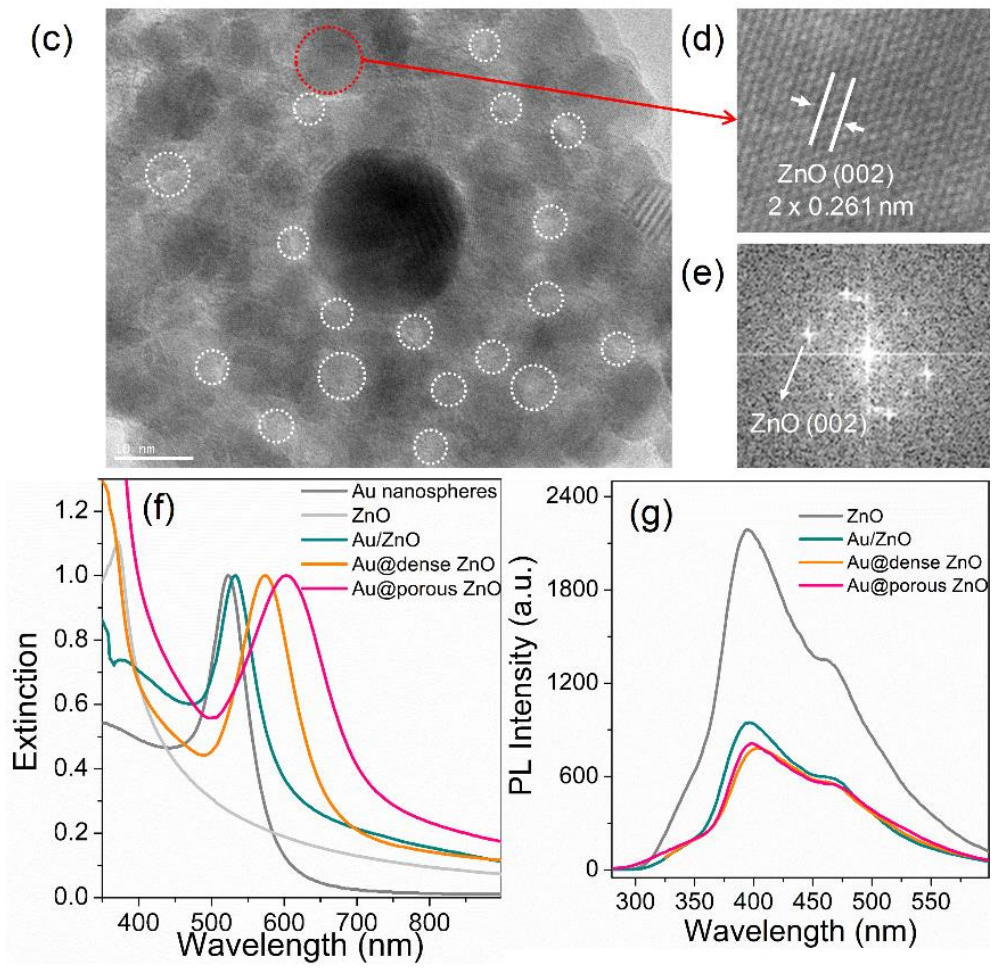

Figure 2. XRD patterns (a) and EDS spectra (b) of the structure-adjustable Au-ZnO hybrids. (c) High-resolution TEM (HRTEM) image of Au@porous ZnO. (d) HRTEM image recorded from the area marked with a red circle in (c). (e) Fast Fourier transform (FFT) pattern of the region indicated by a red dashed circle. (f) Extinction spectra of $\mathrm{Au}, \mathrm{ZnO}$, and structure-adjustable Au-ZnO hybrids. (g) Photoluminescence (PL) spectra of $\mathrm{ZnO}$ and the structure-adjustable Au- $\mathrm{ZnO}$ hybrids.

The extinction spectra of the structure-adjustable $\mathrm{Au}-\mathrm{ZnO}$ hybrids are given in Figure $2 \mathrm{f}$. The $\mathrm{Au}$ nanospheres exhibited a narrow plasmon peak around $520 \mathrm{~nm}$. The plasmon peak of Au@dense $\mathrm{ZnO}$ red-shifted to $578 \mathrm{~nm}$, caused by the increased refractive index of the surrounding medium. For $\mathrm{Au} @$ porous $\mathrm{ZnO}$, the plasmon peak red-shifted to $614 \mathrm{~nm}$. The plasmon peak of Au/ZnO red-shifted slightly, reaching $532 \mathrm{~nm}$. The structure-adjustable Au-ZnO hybrids had a sharp and strong plasmon resonance in the visible light region, laying the foundation for hot electron-driven photocatalysis. Figure $2 \mathrm{~g}$ displays the $\mathrm{PL}$ spectra of $\mathrm{ZnO}$ and the structure-adjustable Au- $\mathrm{ZnO}$ hybrids. The ultraviolet and blue emission intensities of the structure-adjustable $\mathrm{Au}-\mathrm{ZnO}$ hybrids were remarkably decreased compared with those of the pure $\mathrm{ZnO}$, verifying the efficient electron migration and energy between $\mathrm{ZnO}$ and $\mathrm{Au}$.

The photocatalytic hydrogen generation activities of $\mathrm{ZnO}$ and the structure-adjustable $\mathrm{Au}-\mathrm{ZnO}$ hybrids were investigated by using $\mathrm{Na}_{2} \mathrm{~S}$ and $\mathrm{Na}_{2} \mathrm{SO}_{3}$ as sacrificial agents under light irradiation 
$(\lambda>420 \mathrm{~nm})$. As shown in Figure $3 \mathrm{a}, \mathrm{b}$, the pure $\mathrm{ZnO}$ had a low hydrogen generation rate of $0.044 \mathrm{mmol} \mathrm{g}^{-1} \mathrm{~h}^{-1}$. This is because $\mathrm{ZnO}$ had a weak visible light absorption and a fast recombination of electron-hole pairs. Noticeably, the Au@porous $\mathrm{ZnO}$ hybrids had the highest photocatalytic hydrogen generation rate, reaching $0.12 \mathrm{mmol} \mathrm{g}^{-1} \mathrm{~h}^{-1}$, which were $2.75,1.34$, and 1.14 times those of the pure $\mathrm{ZnO}, \mathrm{Au} / \mathrm{ZnO}$, and the $\mathrm{Au} @$ dense $\mathrm{ZnO}$ hybrids.
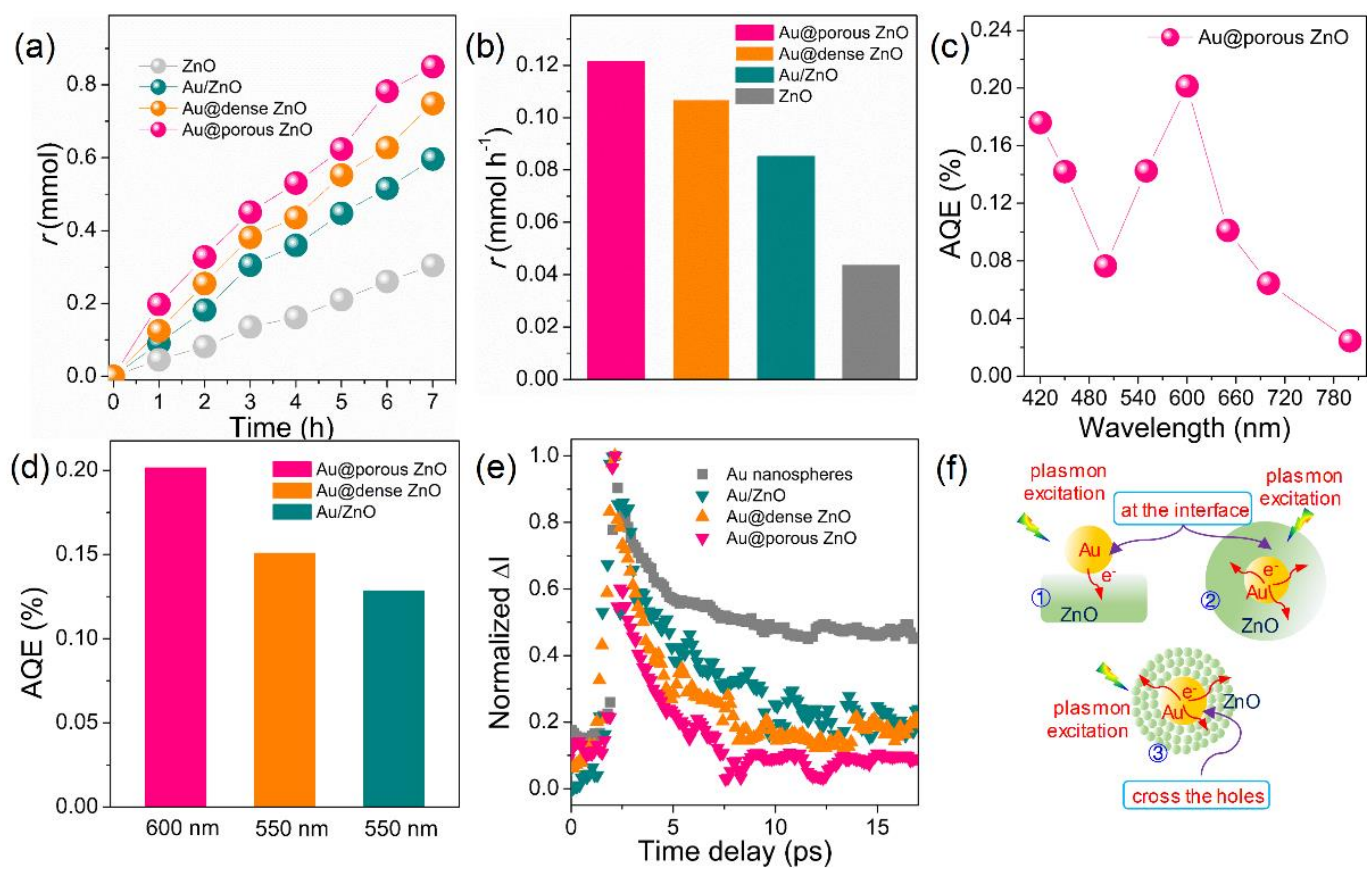

(f)

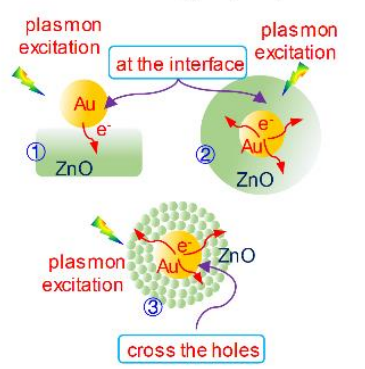

Figure 3. (a,b) Photocatalytic hydrogen generation rates of $\mathrm{ZnO}$ and the structure-adjustable Au- $\mathrm{ZnO}$ hybrids. (c) Apparent quantum efficiency (AQE) of the Au@porous ZnO hybrids. (d) AQEs of the structure-adjustable Au-ZnO hybrids tested at their plasmon resonances. (e) Normalized time-resolved optical differential transmission for $\mathrm{Au}$ and the structure-adjustable $\mathrm{Au}-\mathrm{ZnO}$ hybrids. (f) Schematic illustrating the possible hot electron injection processes in the structure-adjustable Au-ZnO hybrids.

To reveal the mechanism of the improved photocatalytic activity of Au@porous ZnO, the AQE of hydrogen generation was tested using monochromatic light irradiation. As shown in Figure 3c, the AQE of Au@porous $\mathrm{ZnO}$ matched well with its extinction spectrum, revealing that the plasmon excitation was the origin of the enhanced hydrogen generation. In addition, the AQEs of the three types of Au-ZnO hybrids, which were tested around their corresponding plasmon resonance peaks, were given to verify the plasmon-enhanced efficiency. The Au@porous $\mathrm{ZnO}$ hybrids had the highest AQE $(0.21 \%)$ with the irradiation wavelength at the plasmon peak of $600 \mathrm{~nm}$, whereas the AQEs of the $\mathrm{Au} / \mathrm{ZnO}$ and $\mathrm{Au} @$ dense $\mathrm{ZnO}$ catalysts only reached $0.12 \%$ and $0.15 \%$, respectively, with an irradiation wavelength of $550 \mathrm{~nm}$. These results demonstrated that the Au@porous $\mathrm{ZnO}$ hybrids had the highest plasmon-enhanced photocatalytic conversion efficiency upon resonance excitation.

The structure-adjustable Au-ZnO hybrids had almost the same mass ratio of $\mathrm{Au}$, and they had a similar plasmonic light-harvesting ability. However, they showed totally different photocatalytic hydrogen generation efficiencies upon resonance excitation. The different architectures played a key role, which may influence the utilization efficiency of plasmon-induced hot electrons. Ultrafast transient absorption measurements probed around the plasmon peaks were used to investigate the hot electron injection processes, thereby explaining the physical mechanism of a different photocatalytic activity upon resonance excitation. As shown in Figure 3e, the decay rate of $\mathrm{Au} / \mathrm{ZnO}$ was faster than that of the Au nanospheres, which demonstrated that the hot electrons in the Au nanospheres were quickly injected into $\mathrm{ZnO}$. The $\mathrm{Au} @$ dense $\mathrm{ZnO}$ hybrids showed a faster decay rate than $\mathrm{Au} / \mathrm{ZnO}$, indicating a higher hot electron injection efficiency from the Au nanospheres to the $\mathrm{ZnO}$ shells. Noticeably, 
the Au@porous $\mathrm{ZnO}$ hybrids displayed the fastest decay rate, revealing the highest hot electron injection efficiency.

To explain the different hot electron injection efficiencies of the three types of hybrids, the possible hot electrons injection processes were proposed. As shown in Figure $3 \mathrm{f}$, for the three types of $\mathrm{Au}-\mathrm{ZnO}$ hybrids, the hot electron injection occurred at the interface between the Au nanospheres and the $\mathrm{ZnO}$ shells. However, the small contact area of the $\mathrm{Au} / \mathrm{ZnO}$ hybrids limited their hot electron injection efficiency. For the core-shell Au@dense ZnO hybrids, they had a much larger interfacial contact area than that of the $\mathrm{Au} / \mathrm{ZnO}$ hybrids, therefore resulting in faster hot electrons injection. Interestingly, the $\mathrm{Au} @$ porous $\mathrm{ZnO}$ hybrids had the highest hot electron injection efficiency, even though such structures almost had the same thickness of the $\mathrm{ZnO}$ shell and contact area compared with Au@dense ZnO. This is because porous $\mathrm{ZnO}$ nanoshells had abundant holes for hot electron transfer. Hence, hot electrons can not only be injected into the inner $\mathrm{ZnO}$, but also transfer to the outer $\mathrm{ZnO}$. Therefore, the $\mathrm{Au} @$ porous $\mathrm{ZnO}$ hybrids exhibited the highest photocatalytic hydrogen generation rate.

\section{Materials and Methods}

Chloroauric acid $\left(\mathrm{HAuCl}_{4} \cdot 4 \mathrm{H}_{2} \mathrm{O}, 99.99 \%\right)$, sodium hydroxide ( $\left.\mathrm{NaOH}, 99.7 \%\right)$, L-ascorbic acid (AA, $99.7 \%)$, sodium sulfite $\left(\mathrm{Na}_{2} \mathrm{SO}_{3}, 99.5 \%\right)$, sodium sulfide $\left(\mathrm{Na}_{2} \mathrm{~S}, 99.5 \%\right)$, sodium borohydride $\left(\mathrm{NaBH}_{4}\right.$, $96.0 \%)$, zinc acetate $(99.5 \%)$, hexamethylenetetramine $(99.0 \%)$, were purchased from Sinopharm Chemical Reagent Co. Ltd. (Shanghai, China). Hexadecyltrimethylammonium bromide (CTAB, 99.0\%) was purchased from Amresco, Inc. (Solon, OH, USA). Deionized water with a resistivity of about $18.25 \mathrm{M} \Omega \mathrm{cm}$ was used as the solvent in all experiments. Au nanospheres were prepared as previously reported [28]. For the synthesis of structure-adjustable Au-ZnO hybrids, $2 \mathrm{~mL}$ of zinc acetate $(0.1 \mathrm{M})$, $2 \mathrm{~mL}$ of ascorbic acid $(0.1 \mathrm{M})$, and $5 \mathrm{~mL}$ of hexamethylenetetramine $(0.1 \mathrm{M})$ were added to $10 \mathrm{~mL}$ as-prepared $\mathrm{Au}$ nanospheres in an aqueous solution. The mixture was kept at $85^{\circ} \mathrm{C}$ for $8 \mathrm{~h}$ in a vacuum oven. The product (labelled " $\mathrm{A}$ ") was centrifuged, washed by water and dried at $60^{\circ} \mathrm{C}$. To obtain $\mathrm{Au} @$ dense $\mathrm{ZnO}$, the as-prepared " $\mathrm{A}$ " powder was annealed at $200^{\circ} \mathrm{C}$ for $1 \mathrm{~h}$ in air. To obtain $\mathrm{Au} @$ porous $\mathrm{ZnO}$, the as-prepared " $\mathrm{A}$ " powder was dispersed in ultrapure water and annealed at $20{ }^{\circ} \mathrm{C}$ for $1 \mathrm{~h}$ in air. To obtain Au-decorated $\mathrm{ZnO}$, the as-prepared " $\mathrm{A}$ " powder was transferred to a stainless steel autoclave and annealed at $200{ }^{\circ} \mathrm{C}$ in a vacuum oven.

Photocatalytic hydrogen generation measurements were conducted as previously reported [29]. Visible-light photocatalytic hydrogen production tests were conducted with a commercial photocatalytic evaluation system. Briefly, $50 \mathrm{mg}$ of photocatalyst powders were dispersed in $50 \mathrm{~mL}$ of an aqueous solution containing $\mathrm{Na}_{2} \mathrm{SO}_{3}(0.25 \mathrm{M})$ and $\mathrm{Na}_{2} \mathrm{~S}(0.35 \mathrm{M})$ as sacrificial reagents. The light source was a $300 \mathrm{~W}$ Xenon lamp (Zhongjiaojinyuan, Beijing, China) equipped with an ultraviolet cutoff filter $(\lambda>420 \mathrm{~nm})$. The amount of hydrogen gas was automatically analyzed by an online gas chromatograph (Tianmei GC-7920, Beijing, China). The apparent quantum efficiency (AQE) was measured using a series of quartz bandpass filters to obtain the monochromatic light. The photo flux of the incident light was tested by a Ray virtual radiation actinometer (Prefectlight, Beijing, China). The morphologies were obtained with TEM (Hitachi, Tokyo, Japan). XRD patterns were tested on an X-ray diffractometer (Panaco, Holland). The optical properties of the products were analyzed with extinction and photoluminescence (PL) spectra. Femtosecond transient absorption experiments were performed at room temperature by using a pump-probe method. The wavelengths of the pump and the probe were tuned to $560 \mathrm{~nm}$.

\section{Conclusions}

In summary, we have successfully prepared structure-adjustable Au-ZnO hybrids, including Au-decorated $\mathrm{ZnO}$, core-shell Au@dense $\mathrm{ZnO}$, and Au@porous $\mathrm{ZnO}$, for hot electron-driven photocatalytic hydrogen generation. Under light $(\lambda>420 \mathrm{~nm})$ irradiation, the Au@porous ZnO hybrids exhibited the highest photocatalytic hydrogen generation activity from water splitting. The enhanced mechanism can be ascribed to the enhanced utilization efficiency of hot electrons, which was 
caused by the porous $\mathrm{ZnO}$. This work might provide a promising route to designing photocatalytic and photoelectric materials.

Author Contributions: Y.C. performed the experiments; Y.C., S.D., and L.M. contributed to the conceptualization and writing of the manuscript. All authors have read and agreed to the published version of the manuscript.

Funding: This research was funded by the National Natural Science Foundation of China (11904270 and 11904332) and the Natural Science Foundation of Hubei Province (2019CFB169).

Conflicts of Interest: The authors declare no conflicts of interest.

\section{References}

1. Clavero, C. Plasmon-induced hot-electron generation at nanoparticle/metal-oxide interfaces for photovoltaic and photocatalytic devices. Nat. Photonics 2014, 8, 95. [CrossRef]

2. Elbanna, O.; Kim, S.; Fujitsuka, M.; Majima, $\mathrm{T}_{\mathrm{TiO}}$ mesocrystals composited with gold nanorods for highly efficient visible-NIR-photocatalytic hydrogen production. Nano Energy 2017, 35, 1-8. [CrossRef]

3. Brongersma, M.L.; Halas, N.J.; Nordlander, P. Plasmon-induced hot carrier science and technology. Nat. Nanotechnol. 2015, 10, 25. [CrossRef] [PubMed]

4. Wu, K.; Chen, J.; McBride, J.R.; Lian, T. Efficient hot-electron transfer by a plasmon-induced interfacial charge-transfer transition. Science 2015, 349, 632-635. [CrossRef]

5. Sundararaman, R.; Narang, P.; Jermyn, A.S.; Goddard, W.A., III; Atwater, H.A. Theoretical predictions for hot-carrier generation from surface plasmon decay. Nat. Commun. 2014, 5, 1-8. [CrossRef]

6. Brown, A.M.; Sundararaman, R.; Narang, P.; Goddard, W.A., III; Atwater, H.A. Nonradiative plasmon decay and hot carrier dynamics: Effects of phonons, surfaces, and geometry. ACS Nano 2016, 10, 957-966. [CrossRef]

7. Wang, C.; Astruc, D. Nanogold plasmonic photocatalysis for organic synthesis and clean energy conversion. Chem. Soc. Rev. 2014, 43, 7188-7216. [CrossRef]

8. Zhang, Y.; He, S.; Guo, W.; Hu, Y.; Huang, J.; Mulcahy, J.R.; Wei, W.D. Surface-plasmon-driven hot electron photochemistry. Chem. Rev. 2017, 118, 2927-2954. [CrossRef]

9. Li, X.; Zhu, J.; Wei, B. Hybrid nanostructures of metal/two-dimensional nanomaterials for plasmon-enhanced applications. Chem. Soc. Rev. 2016, 45, 3145-3187. [CrossRef]

10. Meng, X.; Liu, L.; Ouyang, S.; Xu, H.; Wang, D.; Zhao, N.; Ye, J. Nanometals for solar-to-chemical energy conversion: From semiconductor-based photocatalysis to plasmon-mediated photocatalysis and photo-thermocatalysis. Adv. Mater. 2016, 28, 6781-6803. [CrossRef]

11. $\mathrm{Wu}, \mathrm{N}$. Plasmonic metal-semiconductor photocatalysts and photoelectrochemical cells: A review. Nanoscale 2018, 10, 2679-2696. [CrossRef] [PubMed]

12. Li, K.; Hogan, N.J.; Kale, M.J.; Halas, N.J.; Nordlander, P.; Christopher, P. Balancing near-field enhancement, absorption, and scattering for effective antenna-reactor plasmonic photocatalysis. Nano Lett. 2017, 17, 3710-3717. [CrossRef] [PubMed]

13. Ma, X.C.; Dai, Y.; Yu, L.; Huang, B.B. Energy transfer in plasmonic photocatalytic composites. Light: Sci. Appl. 2016, 5, e16017. [CrossRef] [PubMed]

14. Ishii, S.; Shinde, S.L.; Nagao, T. Nonmetallic materials for plasmonic hot carrier excitation. Adv. Opt. Mater. 2019, 7, 1800603. [CrossRef]

15. Mascaretti, L.; Dutta, A.; Kment, Š.; Shalaev, V.M.; Boltasseva, A.; Zbořil, R.; Naldoni, A. Plasmon-enhanced photoelectrochemical water splitting for efficient renewable energy storage. Adv. Mater. 2019, 31, 1805513. [CrossRef]

16. Kang, Y.; Gong, Y.; Hu, Z.; Li, Z.; Qiu, Z.; Zhu, X.; Ajayan, P.M.; Fang, Z. Plasmonic hot electron enhanced $\mathrm{MoS}_{2}$ photocatalysis in hydrogen evolution. Nanoscale 2015, 7, 4482-4488. [CrossRef]

17. DuChene, J.S.; Sweeny, B.C.; Johnston-Peck, A.C.; Su, D.; Stach, E.A.; Wei, W.D. Prolonged hot electron dynamics in plasmonic-metal/semiconductor heterostructures with implications for solar photocatalysis. Angew. Chem. Int. Ed. 2014, 53, 7887-7891. [CrossRef]

18. Paul, K.K.; Giri, P.K. Role of surface plasmons and hot electrons on the multi-step photocatalytic decay by defect enriched $\mathrm{Ag} @ \mathrm{TiO}_{2}$ nanorods under visible light. J. Phys. Chem. C 2017, 121, 20016-20030. [CrossRef] 
19. Weng, L.; Zhang, H.; Govorov, A.O.; Ouyang, M. Hierarchical synthesis of non-centrosymmetric hybrid nanostructures and enabled plasmon-driven photocatalysis. Nat. Commun. 2014, 5, 1-10. [CrossRef]

20. Ahn, W.; Ratchford, D.C.; Pehrsson, P.E.; Simpkins, B.S. Surface plasmon polariton-induced hot carrier generation for photocatalysis. Nanoscale 2017, 9, 3010-3022. [CrossRef]

21. Hou, B.; Shen, L.; Shi, H.; Kapadia, R.; Cronin, S.B. Hot electron-driven photocatalytic water splitting. Phys. Chem. Chem. Phys. 2017, 19, 2877-2881. [CrossRef] [PubMed]

22. Kumar, D.; Lee, A.; Lee, T.; Lim, M.; Lim, D.K. Ultrafast and efficient transport of hot plasmonic electrons by graphene for Pt free, highly efficient visible-light responsive photocatalyst. Nano Lett. 2016, 16, 1760-1767. [CrossRef] [PubMed]

23. Waiskopf, N.; Ben-Shahar, Y.; Banin, U. Photocatalytic hybrid semiconductor-metal nanoparticles; from synergistic properties to emerging applications. Adv. Mater. 2018, 30, 1706697. [CrossRef] [PubMed]

24. Lou, Z.; Kim, S.; Fujitsuka, M.; Yang, X.; Li, B.; Majima, T. Anisotropic $\mathrm{Ag}_{2} \mathrm{~S}-\mathrm{Au}$ triangular nanoprisms with desired configuration for plasmonic photocatalytic hydrogen generation in visible/near-infrared region. Adv. Funct. Mater. 2018, 28, 1706969. [CrossRef]

25. Wu, B.; Liu, D.; Mubeen, S.; Chuong, T.T.; Moskovits, M.; Stucky, G.D. Anisotropic growth of $\mathrm{TiO}_{2}$ onto gold nanorods for plasmon-enhanced hydrogen production from water reduction. J. Am. Chem. Soc. 2016, 138, 1114-1117. [CrossRef] [PubMed]

26. Jafari, T.; Moharreri, E.; Amin, A.S.; Miao, R.; Song, W.; Suib, S.L. Photocatalytic water splitting-the untamed dream: A review of recent advances. Molecules 2016, 21, 900. [CrossRef] [PubMed]

27. Zhang, Q.; Gangadharan, D.T.; Liu, Y.; Xu, Z.; Chaker, M.; Ma, D. Recent advancements in plasmon-enhanced visible light-driven water splitting. J. Mater. 2017, 3, 33-50. [CrossRef]

28. Ma, L.; Chen, Y.L.; Yang, X.; Li, H.X.; Ding, S.J.; Hou, H.Y.; Xiong, L.; Qin, P.L.; Chen, X.B. Growth behavior of $\mathrm{Au} / \mathrm{Cu}_{2-x} \mathrm{~S}$ hybrids and their plasmon-enhanced dual-functional catalytic activity. CrystEngComm 2019, 21, 5610-5617. [CrossRef]

29. Ma, L.; Yang, D.J.; Song, X.P.; Li, H.X.; Ding, S.J.; Xiong, L.; Qin, P.L.; Chen, X.B. Pt Decorated (Au nanosphere)/(CuSe ultrathin nanoplate) tangential hybrids for efficient photocatalytic hydrogen generation via dual-plasmon-induced strong VIS-NIR light absorption and interfacial electric field coupling. Sol. RRL 2019, 4, 1900376. [CrossRef] 